\title{
State Rescaling, Contested Space, and Inequality in the Globalizing City-regions of China: Conceptual Issues and Empirical Evidence
}

\author{
Guo Chen
}

Guo Chen, Department of Geography and Global Urban Studies Program, Michigan State University, East Lansing,USA (guochen@msu.edu)

\begin{abstract}
In post-reform China, the spatial forms of cities are defined by two combined forces - a downward decentralization of responsibility for economic development, and an upward centralization of power to larger urban cores. This process of administrative rescaling is creating an "entrepreneurial urban space" in the city cores and "commercialized towns and villages" in the city margins (McGee et al. 2007). As a result of the rescaling, a form of contested space has emerged, mostly in cities and their immediate margins, where local civil society is constantly resisting or adapting to the Chinese urban expansion manifested through territorial reorganization and boundary redefinition. Cities' inner margins (suburbs) have in particular seen the most dramatic increases in population and manufacturing due to migration, housing development, and industrial relocation. This paper seeks to provide a close dissection of the process of rescaling and the production of these contested urban spaces through a spatial lens. In adopting a comparative and case study approach, this paper analyzes census data from three large city-regions in China: Beijing, Shanghai, and Guangzhou to explore two questions: (1) whether this rescaling is creating segmentation, displacement, or polarization in residence and work spaces; and (2) at which scales (district or community) these spatial outcomes are unfolding. The paper concludes that inequalities are increasingly concentrated in the inner margins, where an entrepreneurial city core meets the self-initiated urban expansion of the towns in the outer margins, and farmers, displaced urbanites, rural migrants, and foreign workers aggregate and compete for space.
\end{abstract}

Keywords: urban space, residential space, work space, rescaling, China

\section{Introduction: City-regions and Inequality in the Context of State Rescaling}

Over the late one or two decades since the 1990s, academic study has tended to concentrate on the 'new regionalism' and the rescaling of political processes. There are several reasons for these changes: the 'hollowing out' of the nation-state, as well as governmental devolution and decentralization to the subnational level in conjunction with the increasing autonomous institutional capacities of regions to harness regional economic development (Allmendinger and Tewdwr-Jones, 2000). These research directions have created a renewed interest in regional governance in the U.K. and other European countries. In this context of state reforms, a consensus has emerged on the growing strategic role of city-regions in the global economy (Boudreau, 2003). According to Scott et al. (2001), city-regions are becoming increasingly important because 'globalization has reactivated their significance as bases of all forms of productive activity' (p.11 ). Clashes on economic and cultural issues are becoming pronounced between provincial governments and local municipalities on the one hand, and between the inner city and the suburbs on the other. Furthermore, new forms of city-suburban cooperation, regional coordination, region-wide spatial planning, and metropolitan institutional organization have been promoted in major city-regions. This wave of metropolitan governance reform focused on economic priorities such as 
maintaining territorial competitiveness and attracting external capital investment (Brenner, 2003). Whereas significant aspects of economic regulation have devolved to sub-national institutional levels, major socioeconomic assets have become (re)concentrated in the most globally competitive urban regions and industrial districts, thereby exacerbating uneven intra-national spatial development (Brenner, 2004).

The growth of the city-regions propelled by the rescaling of power and driven by a mixture of sub-national and national goals for boosting competitiveness in the global economy is cause for concern for some commentators at least. For example, some researchers are concerned with the social and spatial consequences of globalization for emerging city-regions (see Fainstein, 2001; Hackworth, 2003; van der Waal and Burgers, 2009). First, evidence from developed countries shows that in large cityregions the economic gap between social groups is increasing. Evidently, city-regions attract people situated at either end of the class hierarchy. The numbers of both highwage professionals and unskilled laborers are rising in city-regions. It is still debatable whether income inequality is increasing because of rising incomes at the top or falling incomes at the bottom, but it has been reported that the inequality level is increasing in many city-regions (Fainstein, 2001). Second, the scale at which inequality is unfolding is shifting. For example, in the U.S. and other countries, sources of inequality in housing have shifted toward local institutional differences instead of resulting from regional- and national-level variables such as federal funding (Hackworth, 2003). Moreover, many researchers have argued that large-scale metropolitan development is associated with spatial fragmentation as well as social fragmentation (Etherington and Jones, 2009; Fainstein, 2001). A spatial dimension of inequality is unfolding in cityregions. As Fainstein (2001) argued, global city-regions draw a significant proportion of high-earning individuals, yet the high cost of living in the core areas of city-regions either forces low-income people into unaffordable housing at the center or pushes them to the periphery. A spatial mismatch between population and jobs could further reinforce existing patterns of inequality.

Similar processes and spatial outcomes occur in developing countries. In particular, changes to established modes of governance, such as the decentralization of the scale at which state institutions operate or the privatization of service delivery, have various impacts on power structures, institutions, livelihoods, and physical landscapes (Batterbury and Fernando, 2006). In fact, problems in city-regions are often more pronounced in developing countries than in developed countries, due to the latter's initial low levels of urbanization, restricted modern sectors, and unevenly developed infrastructure (Scott et al., 2001).

Though urbanization in post-reform China is largely perceived as a 'state project', it has been argued that Chinese cities, especially those of regional and global relevance, are experiencing their own rescaling processes. More specifically, the spatial forms of Chinese cities are defined by two combined forces - a 'downward' force, that is, decentralization of responsibility for economic development, and an 'upward' forces, that is centralization of power to larger urban cores. This process of administrative rescaling is creating an 'entrepreneurial urban space' in the city centers and in the 'commercialized towns and villages' in the city margins (McGee et al., 2007; Smart and Lin, 2007). As a result of this rescaling, a form of 'contested' space has emerged in China, mostly in cities and their immediate margins, wherein local civil society is constantly resisting or adapting to urban expansion manifested through territorial reorganization and boundary redefinition. The inner margins (suburbs) of cities especially have seen the most dramatic population increases due to migration, housing development, and industrial relocation. Note in this paper, margins refer to the areas 
adjacent to a city proper, including inner margins or suburbs and outer margins comprised of rural counties. In the Chinese context, especially for large cities, both areas are under the jurisdiction of the city government.

In particular, the Chinese rescaling process involves a series of interactions and negotiations between the central state and local states (city governments), and it doesn't necessarily entail a simple decentralization in power. Instead, the central state has realigned its functions and has even strengthened its role in some aspects, while granting local states liberty at accumulating resources to build up local competitiveness to participate in the regional or global economy. The mechanisms used include legalizing local states' right to expropriate suburban land, supporting municipal boundary adjustment, promoting a 'city-administrating-counties' system, and allowing a greater share of land leasing revenue returned to the local states (Shen, 2007). In many ways, China's urban spatial development features a state-sponsored, locally-driven urban expansion regime. The several leading large cities, such as Shanghai and Beijing (administratively as the "directly-controlled" municipalities designated by the central government), and Guangzhou are emerging as the most prominent cases of such development.

\section{'Contested' Spaces as a Research Focus}

High levels of inter-connectivity across various scales in city-regions, from local and regional to global, have created spatial structures that are often more complex than those depicted in earlier models such as Gottmann's conception of megalopolis. According to Hall (2001), city-regions have a geographical structure that is quintessentially polycentric. This structure may contain (1) a downtown center often found in the cores of old cities, (2) a newer business center often developing in an old and prestigious residential quarter, (3) an internal-edge city resulting from an earlier shortage of space in traditional centers and speculative development, (4) an externaledge city often located on the axis of a major airport, (5) outermost-edge city complexes located at major stations, and (6) specialized sub-centers for education, entertainment, and sporting complexes, and exhibition and convention centers. Scale-wise, the cityregion can comprise local, regional, and state spaces.

In urban China, perhaps due to the pressure of land shortages and population growths in large city-regions, this spatial fragmentation is more pronounced. Though the inner-city can be accurately described as an 'area of extreme transition' and a 'soft spot' for neoliberal experiments in many developed countries (Hackworth, 2007, p. 13), China's urban margins have bear all the instabilities, ambitions, and chaos generated by the state-initiated expansion regime. According to some scholars (Xie et al., 2007; Zhou and Ma, 2000), the inner margins of Chinese cities (suburbs) have seen more dramatic population increases, relative to the city propers (city cores or city centers) and the outer margins (rural counties adjacent to the cities), due to trends toward greater migration, more housing development, and industrial relocation into the suburbs. Recent studies show that this outward development has gone beyond purely government-initiated relocation of households and polluting industries. Instead, the new round of suburbanization has been driven by investment interests, such as in the construction of suburban villas. As a result, the suburban landscape of large Chinese cities consists of such oddly different communities as (1) slums self-built by migrants, (2) urban villages owned by villagers and rented to migrants, (3) mixed urban villages populated by migrant families in self-built or rented village housing, (4) state-redeveloped towns or villages built over migrant villages, (5) economic spaces with relocated industries and newly constructed low-cost urban welfare housing projects, and (6) new residential 
spaces independent from or extended from those in the city (Xu and Zhou, 2005). The suburbs or inner margins are where an entrepreneurial city core meets the self-initiated urban development of town and rural communities in the outer margins, and where farmers, displaced urbanites, rural migrants, and foreign workers aggregate and compete for space.

City margins, though, are certainly not the only place in which to look for such contestation for space. Pockets of 'urban villages' - vestiges of previous city boundaries and collectively owned by villagers - can still be found located quite centrally within almost every large Chinese city. Therefore, given what we have observed in these contested spaces, the key questions are these: What specific role does the state and its various agents play in shaping this fragmentation and thereby causing further inequality? How do the state and market forces interact? What are the social and spatial manifestations of inequalities in these contested spaces? This paper presents some preliminary results that begin to lay the foundations for this research direction. The following section examines the dynamics that shape the landscape of contested spaces in Chinese city-regions. Next, I discuss inter-related rescaling processes and spatial consequences in the context of three globalizing city-regions in China. I summarize the preliminary observations for these locales. I conclude by briefly considering the dynamics through which the rescaling process is engendering inequalities within China's city-regions and at which scales (district or community) these sociospatial outcomes are unfolding.

\section{Dynamics of Contested Spaces in China: Local States, the Market, and Other Actors}

To understand the spatial inequalities that are arising in the contested spaces of Chinese city-regions, it is necessary to examine the key actors involved in the process of urban development in these cities. Furthermore, it is essential to determine both how these actors interact with the imperatives of capital investment and the spatial strategies pursued by each actor. In the Chinese context, the most important actors during the spatial expansion process are local government and investors. It is important to note that the grassroots are taking on an increasingly strong role in negotiating their rights to the city. However, individuals, families, and communities are generally responding to instead of driving the process of urban spatial development, simply because of the realities of land ownership in China. That is, although the land in both urban and suburban areas is fragmented among various land users such as the city government, state industries and institutes, military units, and the extremely few individuals whose private housing was not confisticated by the state during the socialist period, some even with de facto ownership for permanent use, all land in China is owned by the state and village collectives. The only existing land ownership transaction is for the state to acquire suburban and rural collective land, which often results in nominal costs for the state. This situation means that the local state has the absolute legal right to acquire all suburban rural land for urban development purposes, with the exceptions of land owned by large state-owned enterprises and land used by farmers for housing. The local state is also the one who spearheads the collection of historically fragmented landownership for urban redevelopment. All land-use changes and transfers such as those between a work unit and a developer have to go through the local state.

As a major actor, local governments have played a predominant role in city expansion because they have the indisputable legal right to acquire land and transfer land uses. However, local governments often adopt varying spatial development strategies, leading to a range of spatial effects on the city and the people living in it. 
Most cities are disproportionately driven by a pro-growth strategy, in which the government becomes a corporate state that is primarily motivated by the profit incentive. The single largest asset owned by any local state is the urban land. Shanghai for example grossed nearly 100 billion Yuan of land leasing fees in the 1990s. Such 'land financing' has set the city on a path toward avid expansion and redevelopment. This pro-growth strategy has resulted in residential, commercial, and financial upgrading in the city proper, and large-scale greenfield development on the margins.

Local governments do pursue pro-equity strategies, which are reflected in approaches such as welfare housing construction and significant interventions in the relocation of inner-city residents. Relocation has so far been implemented in a way that displaces the residents from their original city homes, although with some compensation in the form of cash or granted property rights to a new home within the city margins. Statistics have shown that relocated residents are often provided with housing in inconvenient locations for transport. In Shanghai, for example, between 1992 and 2005, a million households were moved from the inner city to the margins. Residents are being moved farther and farther away from city centers - the most recently planned locations for such housing are all outside of the outer ring road, and at least $25 \mathrm{~km}$ from the city center. Welfare housing for the poor has contributed no more than a negligible portion of the new housing constructed since housing privatization started in the 1990s. Most housing built for the poor is located in marginal areas that are not wanted for commercial housing construction purposes. Rural migrants are still largely funneled through the peasant villages on the margins and the few urban villages in the city, that is, if they are not pushed even farther away from the city center. The intensive commodification of public housing stocks and the construction of new stocks are benefiting native urban citizens and asset-owning new migrants, but forging a formidable barrier for the poor and/or non-locals to start a life in the city. Some cities have reformed the hukou, or family registration policy in order to allow more migrants access to city benefits such as subsidized education and housing. However, efforts have been sporadic and they have been more interested in containing the poor in certain locales and supporting them temporarily than in enabling them to integrate into city life.

In contrast, investors or developers have a limited role in the process of urban expansion. On the one hand, as profit-driven organizations, enterprises tend to develop high-priced housing targeting the upper-middle class, located specifically in the margins where land prices are cheaper than in the inner city. On the other hand, enterprises do not have the capacity to fully participate in the housing market, such as bidding for housing under pure market conditions. The local government sets housing prices based on the prices bid by developers. According to some statistics, about 50 to $80 \%$ of the average price of real estate goes into the pockets of local governments (Wang, 2008). In many cases, that price does not reflect the market price and partially contributes to farmers' protests against insufficient compensation and forced eviction on the urban peripheries.

\section{Cases of Chinese City-regions: Shanghai, Guangzhou, and Beijing}

Given the predominant role of the local state in the development of city-regions, in the following sections, I will focus on what state-enacted spatial strategies are shaping inequalities in the contested spaces of three city-regions. Note that although the city margins in China are increasingly contested by multiple actors and groups, these margins are not invariably tied to what we understand as the contested spaces. In China's urban history, the margins are not necessarily contested either. In this paper, we will see how some of these margins become moving contested zones under aggressive 
development, whose boundaries are increasingly difficult to define. In other cases, we will see how contested spaces continue to exist inside the city. In other words, contested spaces are not defined by their relative distance to city cores, or their less urban-style physical landscapes. Instead, the contested space in my study is a spatial category hosting a variety of socially, economically, and politically fragmented groups. It is also a grey area serving as the interface between a top-down state-sponsored city-region expansion regime and all the other forces that don't 'belong'. These spaces can be located inside the city proper or in the inner or outer margins.

The city regions of Guangzhou, Beijing, and Shanghai were selected as the sites for empirical investigation for three clear reasons: (1) the three cities each represent a disparate geographical region of China, (2) the three are the largest city-regions in China and each faces intense pressure in regard to land-use and population, and (3) all three cities are located in regions with relatively high levels of urbanization. The development of industrialized or commercialized towns on the urban periphery, such as in the Yangtze and Pearl River Deltas where Shanghai and Guangzhou are located, often means that such city-regions face much friction and resistance to city expansion and administrative consolidation, from actors across multiple scales.

Within these city-regions, several types of contested spaces are already emerging. They are different in terms of location, urbanization level, and housing and population density. What they share is conflicting interests among pre-existing land users and latecomers in regard to land use. There are at least three types of space at issue. The first type includes contested neighborhood pockets within core city districts, most being peasant communities retained during the process of rapid urban expansion. The Tianhe district of Guangzhou is an example: in the last 15 years of the past century, this district was transformed from a completely suburban rural county into a new downtown area for Guangzhou. However, such fast-paced development has left pockets of urban villages where landless peasants are able to retain their residential lots and upgrade their homes to generate income from cheap rental. Many are in prime locations with extremely high population densities, making them prey to redevelopment but also interestingly 'safe' against forced evictions.

The second type of space, in contrast, is more organized and modern. These are various kinds of new suburban residential districts or towns created on the basis of preexisting towns or rural villages, typically located in the inner margins of large cityregions. Given the relative proximity of these areas to the city and existing town development, the city usually has a strong entrepreneurial interest in them. Facilitated by government re-planning for the town, development does not necessarily involve taking over large areas considered greenfield; instead, it often requires an on-site relocation of the native town community and the consolidation of existing land uses to make space for shiny, middle class-targeted development for the city-region. The Songjiang new town in the Songjiang district of Shanghai is an example of how a commercialized rural county can be remodeled into an upscale, Western European-style new suburban town. The grand project in this area is called the Songjiang University town, which was originally intended to attract both a higher population and further investment to the area. However, so far up-scale commercial housing construction constitutes most of the development.

The third spatial type includes newly developed areas within the outer margins of city-regions. Compared to the other two types, they are located farther away from the city center, but represent the least urbanized and the least densely populated or intensively developed contested spaces. Many of these areas are centered around planned high-tech parks or industrial parks that are supposed to attract investment and 
talent. Sporadic villa and up-scale neighborhoods are built in the vicinity. These parks are 'planted' in distant locations with easy access to inter-city transportation, low land costs, and preferential policies offered by rural counties or suburban districts. However, a location in the rural-urban interface; a dependence on skilled laborers, most of whom commute from the city; and an underdeveloped urban infrastructure often results in a sharp separation of these 'planted parks' from local native communities. These areas are exposed to great uncertainty, therefore, in terms of the relative success of the demographic, economic, and environmental transitions on which they depend. Rural communities and transient migrant enclaves on the peripheries of Beijing, for example, often bear the brunt of the social costs associated with these developments, such as the displacement from agriculture or sustainable sources of income as well as the displacement from low-cost self-sustainable housing.

Note that these three broadly defined types of contested spaces do in fact coexist in some city-region contexts. They only represent several examples of a possible array of types of contested spaces. How they transform and unfold, and how they become home to rising inequalities, though, differ from place to place. I will use the following three city-regions as cases to illustrate the points made thus far. The cases are intended to contextualize the actual rescaling processes, inequalities and the shaping of possible contested spaces, rather than making causal linkages among them. Note although this article is intended to be a conceptual piece, the case study draws from the author's field work in the three cities.

\section{Shanghai}

Shanghai, a city with a higher population than that of Beijing but only two-thirds of its urban constructed area, has experienced a major spatial redistribution of population and economic activities over the past two decades since the 1990s. The city of Shanghai affects the extended urbanized area in the lower Yangtze River Delta, many changes have occurred within the city-region, including the city core, its inner margins and its immediate suburban and rural counties. More specifically, the newly added population and the relocated population have tended to aggregate in or close to the inner margins. Between 1993 and 1999, the population in the inner core decreased by $11.4 \%$, and the population in the outer suburban counties decreased by $3.8 \%$, whereas the populations in the outer core and inner suburbs increased by $5.2 \%$ and $12.9 \%$, respectively.

The initial sociospatial changes in Shanghai's landscape in the 1990s were triggered by the rescaling of state power. Indeed, no other city in China has experienced more profound consequences due to decentralization than has Shanghai. However, such a rescaling process occurred on two levels: first, a coalition developed between the central state and the municipal government in regard to repositioning Shanghai as the 'dragonhead' of the Chinese economy; second, the devolution of some municipal functions transferred power to district governments. As part of the central state's reform plan, the fiscal decentralization of the late 1980s and early 1990s allowed Shanghai more autonomy on the expenditure of its own tax revenue and improved the Shanghai municipal government's positioning enabling it to compete against other promising Chinese cities. When Shanghai was re-promoted by the state as the new front for development in the early 1990s, the city was actually experiencing a slow-down in economic development. By setting up a new district in Pudong, the municipality gained new momentum for attracting foreign direct investment. During the process, the municipality contributed land assets but little else to the development of the new district. With its decentralization of urban management, land market regulation, and 
'land financing' from the municipality to district governments, the Pudong model created much excitement among other district governments, which became motivated to pursue similar schemes.

Clearly, the municipality can both scale up and scale down its development. As the municipality rapidly assumes its global functions and accentuates its central position in the Yangtze River Delta region, the urban margins for development are being pushed farther beyond existing inner suburbs. As Figure 1 shows, between 2004 and 2007, the city core (including the inner core and the outer core) continued to lose population, largely due to urban redevelopment. Yet, three of the four inner suburban districts (Pudong, Minhang, Baoshan, and Jiading) continued to experience the highest rates of population growth among all districts, indicating a continued trend of suburbanization. However, what is interesting is that five of the six outer-suburban districts (Songjiang, Jinshan, Qinpu, Nanhui, Fengxian, and Chongming) were also experiencing population growth.
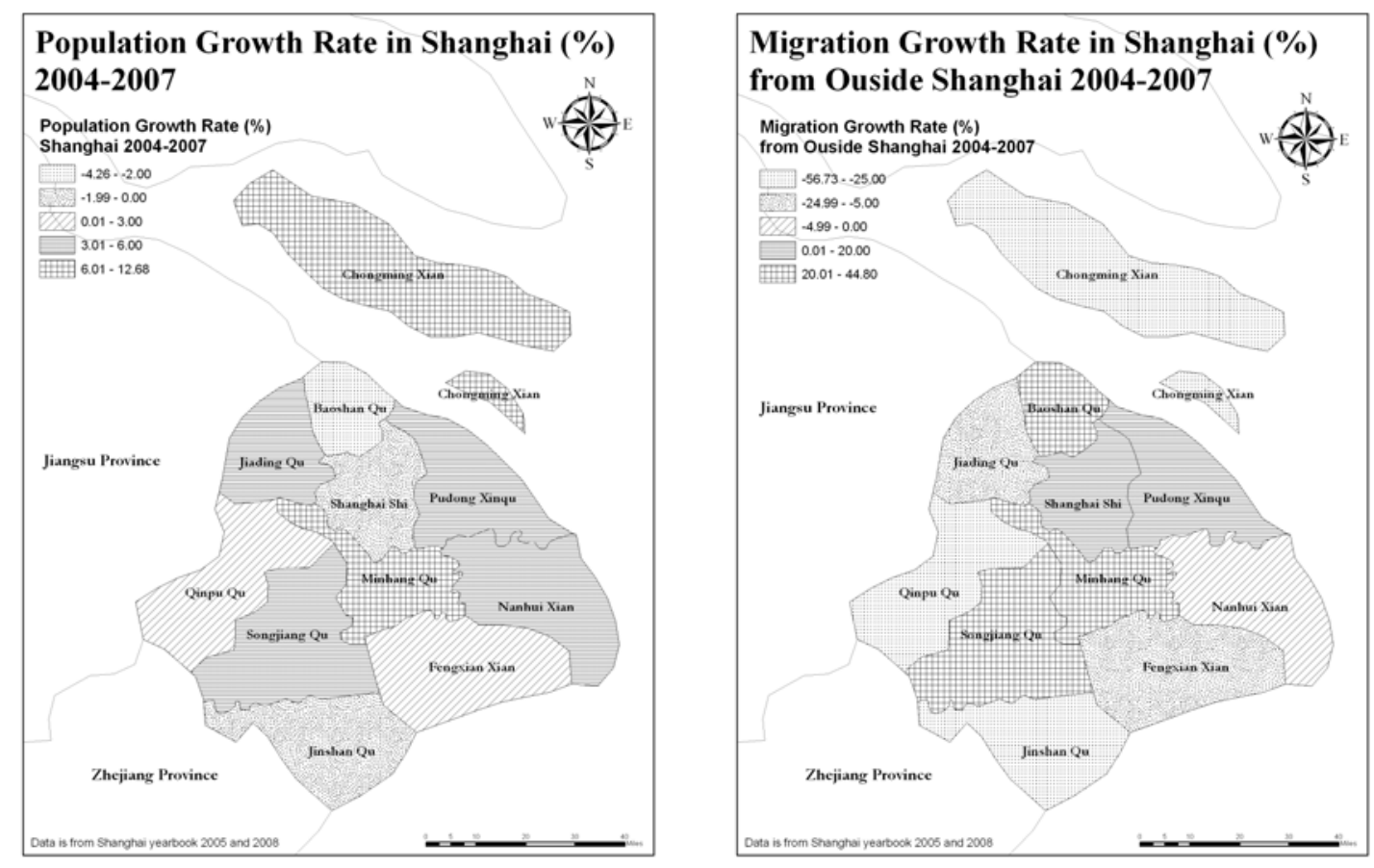

Figure 1: Population Growth and Migrant Growth in Shanghai’s Districts, 2004-2007

This suggests that though the city can scale up its development, it can also effectively use strategies such as promoting territorial consolidation and inter-district competition to scale down developmental objectives to locales. During the tenth fiveyear-plan period, the municipality launched a 'one-city nine-towns' blueprint, in which nine suburban towns were selected for up-scale housing development to counter the flow of migrants and homebuyers toward the city core and inner margins of Shanghai. Since then, the suburban counties have become home to investors, second-home buyers, foreign and domestic migrants, and peasants who have become urbanites. The Songjiang district referred to above is an example of how urban margins have become contested spaces among natives and migrants of all kinds of origins, under the strong guidance of the municipal government (i.e. in promoting a unified Songjiang community). Between 2000 and 2005, the district attracted 0.22 million migrants, the majority of whom came from outside Shanghai. However, the majority were migrant 
workers drawn to the industrial parks who could only afford to rent peasant housing. The new housing in Songjiang comprised large apartments and villas (25\%) that had been designed to interest second-home buyers and investors; however, the housing vacancy rate remained high because the town is too far from jobs for its targeted middle-income working families and too expensive for migrant workers. Clearly, the new district has become a contested space where a state-initiated urban vision supersedes the local interest that would prefer rural industrialization or commercialization. In this case, a master plan envisioned by the city-region from topdown has effectively subdued that of the native community.

\section{Guangzhou}

In contrast to Shanghai, where the municipal and district governments are considered successful and powerful actors in bringing the city to the global stage, the Guangzhou government has been less clear about the city's position. Although it is the provincial capital city of Guangdong province, which is at the forefront of market reform in China, Guangzhou had arguably lost its leading edge in the region's economy by the end of the 1990s, due to the strengthened role of Hong Kong as the regional leader, the success of the designated special economic zone of Shenzhen, and the rise of a number of 'star' satellite cities such as Foshan, Dongguan, and Zhongshan.

The spatial strategies undertaken by the Guangzhou government certainly differ from those in Shanghai. The city of Guangzhou experienced an explosive expansion in the 1990s, partly due to its laissez-faire stance toward urban development. Instead of strategically creating a new district taking over some of the old inner city's functions, the city converted adjacent suburbs into city districts, which results in an expansion of constructed area by 2.5 times its original size during the last 25 years of the 20th century. This expansion was partly driven by the actual need for industrial or housing development. The interspersed urban villages collectively owned by former villagers have largely contributed to the chaotic expansion of the city. Although on the good side, these villages provide affordable rental housing for rural migrants to the city, the high density of buildings in these villages often creates high redevelopment costs. This makes redevelopment a formidable task for municipal government and developers, and thus contributes to the further expansion of the city.

Such a mosaic-like sociospatial landscape reflects the weak role of the municipality in pursuing urban spatial development under free market conditions coupled with strong grassroots forces that have long characterized the region. The city's Tianhe district is a successful example of how a municipal government can best take advantage of opportunities offered by national events such as hosting the All China Games in 1987 to 'land finance' and trigger real estate development in a newly districted suburban area. The district is now part of the city core, and it is one of the most rapidly developing districts in Guangzhou (see Figure 2). However, the new Central Business District, Zhujiang new town, in the Tianhe district, remained unfinished project for almost a decade since the mid 1990s. The highly segmented land, divided by the municipality with the intention of realizing the highest possible profits from leasing the land, led to a real estate market bubble in the area. The decision to reserve former villagers' rights to their collectively owned land (including densely built properties) that takes up 87 acres of the whole 8.7 square kilometers of this area further contributed to the highly segmented land use and to a high level of inequality. Guangzhou's contested spaces are hence distributed across the city like a checkerboard due to its inability to either scale up or scale down its development in the face of strong intra-regional competition and land constraints. However, due to the entrepreneurial 
spirit of local communities and the strong role played by grassroots communities such as village collectives in urban development, few grievances are seen in the contested spaces.
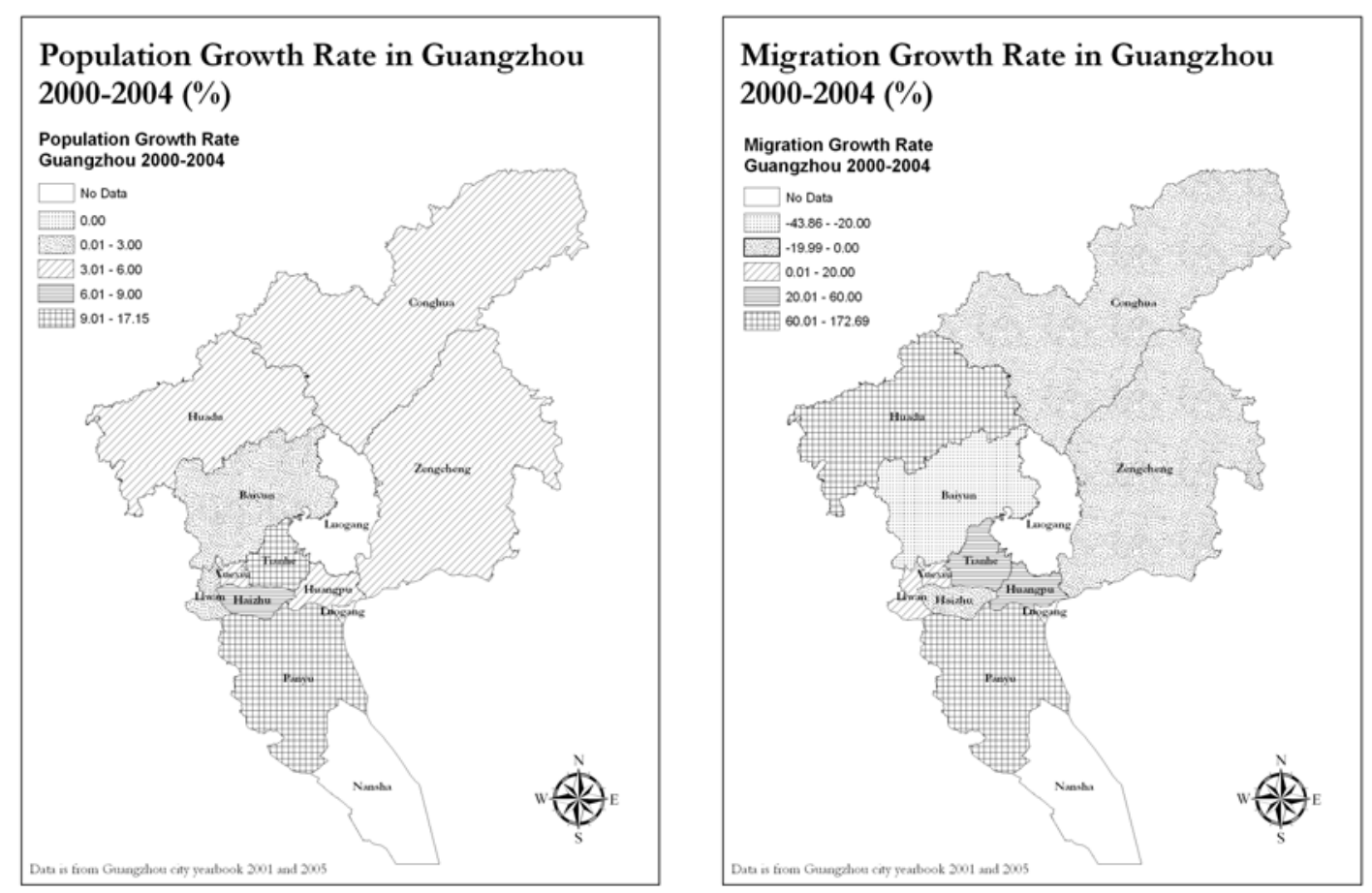

Figure 2: Population Growth and Migrant Growth in Guangzhou's Districts, 2000-2004

\section{Beijing}

Compared to Shanghai and Guangzhou, Beijing presents itself as an exceptional case to either the municipality-dominated model or the laissez faire model due to its proximity to the central government and its lack of bottom-up rural industrialization processes. Beijing's spatial development has been faced with fewer constraints posed by existing land users, as compared to Shanghai and Guangzhou. By the end of the 1990s, Beijing's urban development had been characterized as a typical 'ring-road expansion', or concentric-model of expansion, slightly skewed toward the northwest and along major transportation lines. Since then, the concentric model has been modified by the development surrounding the Olympic Games facilities and new science and tech parks such as Shangdi and Yizhuang. Before 1990, most residential land use was controlled within its third ring road. Since 1990, several mega residential projects such as Wangjing, Tiantongyuan, and Huilongguan have largely contributed to the expansion of the city toward its fourth and fifth ring roads. Since 2000, such expansion has been pushed farther toward the outer suburban districts and rural counties, such as Tongzhou, Daxing, and Shunyi. As the second decade of the $21^{\text {st }}$ century begins, though, the suburban areas of Beijing have become the most populated among the three case cities. Housing needs from relocated inner-city residents and new migrants have been the main drivers of this development.

Though Beijing has historically been less in the spotlight of economic development than the other two case cities, the 2008 Olympic Games triggered efforts to boost the city's global competitiveness. Strategies used are less focused on interdistrict competition and annexation and more targeted to municipality-district collaboration in redesigning the functions of districts. In 2010, the four inner-city 
districts were combined into two districts to strengthen the functionality of the city core as a cultural, political, economic, and historical center. The motivation for this consolidation was a state-sanctioned plan to develop Beijing as a 'world city of Chinese characteristics' - a plan that has certainly put Beijing in an interesting position against Shanghai. Meanwhile, the city has several development zones such as Yizhuang and several newly planned ones in the southern districts of the city. Given the traditional residential preference for the northeast and northwest, the city has shown patterns of inequality among its districts and sub-districts. However, new high-tech and industrial parks may reduce inter-district inequality and then increase intra-district inequality, shifting inequality across scales. The mass demolition of urban villages and slumcondition neighborhoods in order to give way to municipality or district plans for economic and physical upgrading also poses a question about the future of the non-local poor who constitute the majority of the people living in these communities. While onsite relocation plans are set for the natives who own the housing, migrant renters will be effectively pushed away, forced to colonize the next village. Clearly, in a city-region that is also home to the central state, whether any space considered contested truly is so is a question that should be asked. Much has been reported on the 'super' compensation packages paid to native residents, but often ignored are the migrants who live in the enclaves and slums that are bearing the costs of redevelopment.

\section{Conclusion}

This paper offers some insights into the conceptual issues and empirical evidence, and spatial outcomes of the dynamics of contested spaces in contemporary China. It concludes that the spatial development of leading city-regions in China is part of the state-led urbanization project largely driven by land profits and executed through various rescaling strategies. Although all three city-regions are important on the same hierarchical level, each uses a different combination of strategies. It is certainly true that China's city-regions attract jobs at both the top and bottom of the pay scale. And, compared to the West, the income inequality may be more drastic given the low income levels of migrants exploited by the Hukou system. Also, a strong role of the local state often complicates the spatial patterns of inequality. The spatial configuration of inequalities is beyond the scope of this paper. Yet from the cases outlined, we can surmise that the rise of city-regions in China is concurrent with a noticeable trend of shifting inequalities from the scales of geographical region, city, and district to the neighborhood and individual levels. Inequalities appear to increasingly occur along the lines of neighborhood boundaries, such as those between up-scale housing complexes and migrant villages. More important are the processes shaping the inequalities. Unlike in the West, due to a unique set of state rescaling processes, the local state plays a pivotal role in both creatively destructing and consolidating the fragmented inner-city spaces for redevelopment and aggressively obtaining suburban spaces for further expansion. While the city center is still largely favored by the local state to attract foreign investments, the margins and those few slum pockets left in the city center are treated as both the reserved land to cash for further development and the 'backyard' to contain and recycle the 'undeserved' communities by the city, such as migrant labor, poor urban residents, relocated industries, and landless peasants. The contested spaces are both hotspots witnessing the changing sociospatial inequalities and a possible space for grassroots mobilization vis-a-vis the state urban regime. 


\section{Acknowledgments}

This paper is based on a project funded by the MSU-IRGP. This author wishes to thank Jia Feng for creating the maps.

\section{References}

Allmendinger, P. and Tewdwr-Jones, M. (2000), 'Spatial dimensions and institutional uncertainties of planning and the 'new regionalism', Environment and Planning C: Government and Policy 18:6, 711-726.

Batterbury, S.P.J. and Fernando, J.L. (2006), 'Rescaling governance and the impacts of political and environmental decentralization: an introduction', World Development 34:11, 1851-1863.

Boudreau, J.A. (2003), 'The politics of territorialization: regionalism, localism and other isms ... the case of Montreal', Journal of Urban Affairs 25:2, 179-199.

Brenner, N. (2003), 'Metropolitan institutional reform and the rescaling of state space in contemporary Western Europe', European Urban and Regional Studies 10:4, 297-324.

Brenner, N. (2004), 'Urban governance and the production of new state spaces in Western Europe, 1960-2000', Review of International Political Economy 11:3, 447-488.

Etherington, D. and Jones, M. (2009), 'City-Regions: New Geographies of Uneven Development and Inequality', Regional Studies 43, 247-265.

Fainstein, S. (2001), 'Inequality in global city-regions', in A. Scott (ed.), Global cityregions: trends, theory, policy (New York: Oxford University Press).

Hackworth, J. (2003), 'Public housing and the rescaling of regulation in the USA', Environment and Planning A 35:3, 531-549.

Hackworth, J. (2007), The Neoliberal City: Governance, Ideology, and Development in American Urbanism (Ithaca and London: Cornell University Press).

Hall, P. (2001), 'Global city-regions in the twenty-first century', in A. Scott (ed.), Global city-regions: trends, theory, policy (New York: Oxford University Press).

McGee, T.G., Lin, G.C.S., Marton, A.M., Wang, M.Y.L., \& Wu, J. (2007), China's urban space: development under market socialism (New York: Routledge).

Scott, A., Agnew, J., Soja, E.W. and Storper, M. (2001), 'Global city-regions', in A. Scott (ed.), Global city-regions: trends, theory, policy ( New York: Oxford University Press).

Shen, J. (2007), 'Scale, state and the city: Urban transformation in post-reform China', Habitat International 31:3-4, 303-316.

Smart, A. and Lin, G.C.S. (2007), 'Local capitalisms, local citizenship and translocality: Rescaling from below in the Pearl River Delta region, China', International Journal of Urban and Regional Research 31:2, 280-302.

van der Waal, J. and Burgers, J. (2009), 'Unravelling the Global City Debate on Social Inequality: A Firm-level Analysis of Wage Inequality in Amsterdam and Rotterdam', Urban Studies 46, 2715-2729.

Wang, L. (2008), Da Chengshi Bianyuan Diqu Kongjian Zhenghe yu Shequ Fazhan (Spatial consolidation and community development in the margins of metropolises) (Beijing: China Architecture and Building Press).

Xie, Y.C., Fang, C.L., Lin, G.C.S., Gong, H.M. and Qiao, B. (2007), 'Tempo-spatial patterns of land use changes and urban development in globalizing China: a study of Beijing', Sensors 7:11, 2881-2906. 
Xu, J. and Zhou, H. (2005), Chengshi Bianyuan Qudai Shengtai Guihua Jianshe (Ecological Planning of Urban Margins) (Beijing: China Architecture and Building Press).

Zhou, Y.X. and Ma, L.J.C. (2000), 'Economic restructuring and suburbanization in China', Urban Geography 21:3, 205-236. 